\title{
CRESCIMENTO DE MUDAS E PRODUTIVIDADE DE MINIJARDINS CLONAIS DE EUCALIPTO TRATADOS COM RIZOBACTÉRIAS SELECIONADAS ${ }^{1}$
}

Reginaldo Gonçalves Mafia², Acelino Couto Alfenas² ${ }^{2}$ Eraclides Maria Ferreira² ${ }^{2}$ Talyta Galafazzi Zarpelon ${ }^{2}$ e Leandro de Siqueira ${ }^{3}$

\begin{abstract}
RESUMO - O efeito de rizobactérias promotoras do crescimento foi avaliado sobre a produção de biomassa radicular, número de miniestacas por minicepa e produtividade de minijardins clonais (número de miniestacas $x$ porcentagem de enraizamento) de eucalipto, em viveiro. Com exceção do clone 57, em todos os demais testados foi observado incremento da biomassa radicular, com média igual a 53, 52 e 69\%, respectivamente, nos clones 129, 1274 e 7074. Em geral, verificaram-se diferenças significativas em produção de miniestacas, mas não no índice de produtividade. $\mathrm{O}$ isolado $\mathrm{S} 1$ destacou-se quanto à produção de miniestacas, com incrementos que variaram de 11 a $23 \%$ para os clones 129 e 1274 , respectivamente. Para o clone 7074, o incremento médio foi de $15 \%$. Os resultados indicam claramente que rizobactérias podem ser utilizadas para maximizar a propagação vegetativa do eucalipto, por estaquia.
\end{abstract}

Palavras-chave: Eucalipto, rizobactérias, propagação clonal e minijardim clonal.

\section{GROWTH OF CUTTINGS AND PRODUCTIVITY OF MINI-CLONAL HEDGES, TREATED WITH SELECTED RHIZOBACTERIA}

\begin{abstract}
The effect of plant growth promoting rhizobacteria was evaluated for root biomass of cuttings, number of mini-cuttings per mini-stump and productivity of mini-clonal hedges (number of mini-cuttings $x$ rooting percent) of eucalyptus in the nursery. Except for clone 57, all other showed increase in root biomass, with an average of 53, 52 and 69\% for clones 129, 1274, and 7074 respectively. In general, significant differences were found for mini-cutting production, but not for the productivity index (number of mini-cuttings $x$ rooting percent). Isolate $S 1$ had a substantial effect on the production of mini-cuttings, with increases varying from 11 to $23 \%$ for clones 129 and 1274 respectively. For clone 7074, the average increase was 15\%. The results clearly indicated that rhizobacteria could be employed to maximize the vegetative propagation of eucalyptus by cutting.
\end{abstract}

Keywords: Eucalypt, rhizobacteria, clonal propagation, mini-clonal hedges.

\section{INTRODUÇÃO}

Os plantios de eucalipto suprem hoje, no Brasil, a demanda por madeira com propriedades tecnológicas e silviculturais específicas de diversos setores industriais, notadamente o de papel e celulose, carvão vegetal, postes, moirões de cerca e, mais recentemente, o de madeira serrada. A produção de mudas é feita principalmente por meio da clonagem, a qual garante a manutenção plena das características da planta-matrizelite selecionada e a implantação de talhões uniformes de elevada produtividade, incluindo resistência a doenças (ALFENAS et al., 2004).

\footnotetext{
${ }^{1}$ Recebido em 05.10.2004 e aceito para publicação em 10.08.2005.

${ }^{2}$ Departamento de Fitopatologia, Universidade Federal de Viçosa - UFV, 36570-000 Viçosa - MG.

${ }^{3}$ Cia. Suzano Bahia Sul S.A., 18200-000 Itapetininga - SP. E-mail: <aalfenas@ufv.br>.
} 
A propagação clonal de eucalipto, desde a sua introdução no Brasil, sofreu grandes avanços, o que culminou com o desenvolvimento de três técnicas de produção, designadas cronologicamente macroestaquia, microestaquia e miniestaquia (ASSIS, 2001). Em virtude de uma série de vantagens, como menores custos relacionados com a implantação e manutenção dos minijardins, maior facilidade de colheita e menores custos com transporte e processamento de brotações, maior controle da irrigação e nutrição das minicepas, alto grau de juvenilidade das brotações, menores variações sazonais e maior velocidade de enraizamento, entre outros, a miniestaquia tem sido hoje a técnica de propagação mais comumente empregada no país. Por essa técnica, mudas obtidas a partir de qualquer uma das técnicas de propagação são manejadas para formar minicepas produtoras de propágulos (miniestacas) para enraizamento. Embora existam vários tipos de minijardins clonais, o estabelecimento de minicepas em canaletões de amianto ou concreto com leito de areia e fertirrigação por gotejamento é atualmente o mais empregado. Nesse sistema, obtém-se uma produtividade de aproximadamente 10.000 a 12.000 miniestacas $/ \mathrm{m}^{2} / \mathrm{ano}$, embora existam variações conforme o material genético, idade das minicepas e tratos culturais, entre outros fatores (ALFENAS et al., 2004).

Na propagação clonal do eucalipto por miniestaquia, dois fatores são críticos para maximizar a produção: a produtividade de brotos para estaquia e a capacidade de enraizamento do material genético. Nesse sentido, todos os esforços devem ser despendidos para otimizar, de forma concatenada, esses dois fatores. Assim, toda tecnologia que otimize as condições de crescimento e produção das minicepas favorece diretamente a capacidade produtiva do viveiro.

No substrato de crescimento de plantas, existe normalmente um grande número de microrganismos, incluindo bactérias, fungos, actinomicetos, protozoários e algas. Entretanto, as bactérias são o tipo mais abundante, dados o seu rápido crescimento e a habilidade de utilizar ampla gama de compostos como fonte de carbono e nitrogênio. Esse fato, aliado ao suprimento constante de compostos orgânicos, fornecidos pelas raízes, possibilita a ocorrência, na rizosfera, de uma ampla e diversificada população bacteriana (GLICK, 1995).
Atualmente, bactérias benéficas às plantas e de vida livre no solo têm sido denominadas rizobactérias promotoras do crescimento de plantas (PGPR - Plant Growth-Promoting Rhizobacteria) (KLOEPPER et al., 1989) ou como bactérias capazes de incrementar a produção (YIB - Yield-Increasing Bacteria) (PIAO et al., 1992), as quais tem demonstrado potencial para o desenvolvimento de sistemas sustentáveis de produção (PAN et al., 1999). A promoção de crescimento pode ocorrer de formas indireta ou direta. No primeiro caso, as rizobactérias reduzem ou previnem os efeitos negativos de um ou mais microrganismos patogênicos e, ou, deletérios ao crescimento. Em contrapartida, o efeito direto na promoção de crescimento ocorre a partir do fornecimento de compostos que atuam como reguladores de crescimento da planta ou que facilitam a absorção de nutrientes (GLICK, 1995).

Fertilizantes bacterianos não simbiontes foram empregados já no final do século XIX (1885), na antiga União Soviética. Nesse mesmo país, em 1958 foram utilizados em cerca de $10^{7}$ ha de $50-70 \%$ das principais culturas e propiciaram um incremento de $10-20 \%$ na sua produtividade (BROWN, 1974). No entanto, somente a partir do final da década de 1970 é que surgiram trabalhos que apontaram, de forma consistente, o papel das rizobactérias e procuraram elucidar seus mecanismos de ação como promotores de crescimento. Dentre esses, a produção ou a alteração dos níveis de fitormônios têm explicado, em grande parte, o efeito observado em várias culturas. Diversos microrganismos são capazes de produzir ácido indolacético (AIA), incluindo bactérias epifíticas e colonizadoras de tecidos vegetais (PATTEN e GLICK, 1996). Em geral, tem sido sugerido que mais de $80 \%$ das bactérias isoladas da rizosfera são capazes de produzir esse regulador de crescimento (PRIKRYL et al., 1985; LOPER e SCHROTH, 1986; LEINHOS e VACEK, 1994). A produção de citocininas desponta como o principal fator responsável pelo estímulo ao crescimento de plantas. Em uma seleção de rizobactérias incluindo espécies de Pseudomonas e Serratia, observouse uma relação entre indução de alongamento radicular e produção de certas citocininas (BUCHENAUER, 1998). Outro estudo indicou que o crescimento de rabanete cv. "Cherry Belle" foi incrementado por um isolado de Pseudomonas produtor de compostos com atividade de citocinina (SALAMONE et al., 1997). Outro mecanismo essencial de promoção de crescimento de plantas referese à redução da concentração de etileno na planta, 
pelo incremento da atividade da enzima 1-aminociclopropano-1-carboxílico (ACC) deaminase (GLICK et al., 1994, 1995; HALL et al., 1996).

Além da produção ou alteração nos níveis dos reguladores de crescimento, rizobactérias podem promover o crescimento pelo biocontrole de doenças ou inibição de microrganismos deletérios ao desenvolvimento vegetal, seja pela competição por espaço e nutrientes (De LEIJ et al., 1995), produção de sideróforos (BUCHENAUER, 1998), antibióticos (ELLIS et al., 1979) e compostos voláteis (VOISARD et al., 1989), sem contar, ainda, a habilidade em liberar nutrientes a partir do solo pela produção de enzimas, como fosfatases, sulfatases etc. (De LEIJ e LYNCH, 1997).

Neste trabalho, avaliou-se o efeito de rizobactérias sobre o crescimento de mudas e produtividade de minicepas de eucalipto estabelecidas em leito de areia, com fertirrigação por gotejamento.

\section{MATERIAL E MÉTODOS}

\section{Isolados de rizobactérias e preparo das suspensões}

Empregaram-se quatro isolados de rizobactérias (FL2 - Pseudomonas aeruginosa (Schroeter) Migula; 3918 - Bacillus subtilis Cohn; S1 - Bacillus subtilis Cohn; e MF2 - Pseudomonas sp. Migula, obtidos a partir da rizosfera de mudas clonais de eucalipto de diferentes regiões do país. Essas bactérias foram préselecionadas pela capacidade em promover incremento na biomassa de raízes e induzir o enraizamento adventício (TEIXEIRA, 2001). Após a identificação por meio da análise filogenética de seqüências parciais de DNA ribossomal 16S (rDNA 16S), os isolados foram depositados na coleção do Laboratório de Patologia Florestal (UFV).

Para proceder ao preparo das suspensões rizobacterianas, cada isolado foi cultivado separadamente em meio de Kado e Heskett (1970) a $27^{\circ} \mathrm{C}$, no escuro. Após 48 h, as colônias bacterianas foram recolhidas em solução salina ( $\mathrm{NaCl} 0,85 \%)$. A concentração de cada suspensão foi ajustada de acordo com a correlação entre a densidade ótica e número de unidades formadoras de colônias (u.f.c./mL) para 0,2 Abs. (540 nm), o que corresponde aproximadamente a $10^{8}$ u.f.c./mL. As suspensões foram mantidas sob refrigeração até a sua utilização.

\section{Produção das mudas para instalação do minijardim clonal}

Depois de proceder ao preparo das suspensões de rizobactérias, cada isolado foi adicionado em substrato constituído de casca de arroz carbonizada e vermiculita (1:1), previamente enriquecido com macro e micronutrientes (Quadro 1), na proporção de 0,1 $\mathrm{mL} / \mathrm{cm}^{3}$ de substrato, seguido de homogeneização em misturador do tipo betoneira. Após o preenchimento dos tubetes $\left(50 \mathrm{~cm}^{3}\right)$, miniestacas de quatro clones de eucalipto foram estaqueadas e mantidas por 25 dias em casa de enraizamento, dotada de sistema de irrigação por nebulização. Decorrido esse período, as mudas foram transferidas para área de sombreamento $(50 \%)$ e, após sete dias, para canteiros a céu aberto. Após completar 70 dias de idade, as mudas foram podadas a $10 \mathrm{~cm}$ de altura, visando à formação de minicepas produtoras de propágulos, as quais, após a pré-formação, foram replantadas em canaletões com leito de areia e fertirrigação por gotejamento.

\section{Efeito de rizobactérias sobre o crescimento radicular}

Avaliou-se a biomassa radicular dos quatro clones submetidos ao enraizamento em substrato previamente tratado com rizobactérias. Para isso, decorridos 30 dias do estaqueamento, removeram-se 40 mudas de cada repetição e, após a eliminação dos resíduos de substrato e separação da parte aérea do sistema radicular, procedeuse à secagem das raízes a $70^{\circ} \mathrm{C}$ até atingir massa constante. Após esse período em estufa, determinou-se a biomassa radicular seca $(\mathrm{mg})$ por miniestaca enraizada.

Quadro 1 - Adubação com macro e micronutrientes empregada no substrato de enraizamento constituído de casca de arroz carbonizada e vermiculita (1/1)

Table 1 - Fertilization with macro and micronutrients applied to the rooting substrate consisted of carbonized rice bark and vermiculite (1/1)

\begin{tabular}{lcc}
\hline Fertilizante & Dose $\left(\mathrm{kg} / \mathrm{m}^{3}\right)$ & Forma de Aplicação \\
\hline Superfosfato simples & 8,000 & Direta \\
Sulfato de amônio & 1,042 & Via solução \\
Cloreto de potássio & 0,208 & Via solução \\
Sulfato de zinco & 0,014 & Via solução \\
Sulfato de cobre & 0,014 & Via solução \\
Sulfato de manganês & 0,014 & Via solução \\
Ácido bórico & 0,028 & Via solução \\
\hline
\end{tabular}

R. Árvore, Viçosa-MG, v.29, n.6, p.843-851, 2005 


\section{Efeito de rizobactérias sobre a produtividade do minijardim clonal}

Após o estabelecimento do minijardim clonal com minicepas produzidas a partir de mudas propagadas em substrato tratado com rizobactérias, realizaram-se coletas quinzenais de acordo com a rotina comercial normal, sendo quantificado o número de miniestacas produzidas por minicepa (NM) em cada coleta. Estas foram em seguida estaqueadas no mesmo tipo de substrato citado anteriormente, sem aplicação de rizobactérias, e mantidas nas mesmas condições de enraizamento descritas anteriormente. Após 25 dias na casa de enraizamento, avaliou-se a porcentagem de enraizamento em cada repetição. De posse dos valores médios relativos à produção de miniestacas por minicepa (NM) e do enraizamento médio $(\mathrm{E})$, determinou-se o índice de produtividade (IP) definido por: IP $=$ NM $\times$ E (\%).

Para avaliar o efeito das rizobactérias sobre a produção de miniestacas e sobre a produtividade (IP), comparam-se estatisticamente os valores acumulados de ambas as variáveis pelo método da área abaixo da curva, rotineiramente empregado em estudos de epidemiologia (CAMPBELL e MADDEN, 1990).

\section{Delineamento experimental e análises estatísticas}

Os experimentos foram realizados no viveiro da Cenibra S.A., em Belo Oriente, Minas Gerais. Os ensaios foram conduzidos, para cada clone, em delineamento inteiramente casualizado, composto de cinco repetições por tratamento, cada qual com 40 mudas ou 40 minicepas para análise do efeito de rizobactérias sobre o crescimento e produtividade de minijardim clonal de eucalipto, respectivamente. Os dados de cada ensaio foram submetidos à análise de variância (ANOVA), aplicando-se o teste F, no nível de 5\% de probabilidade, e posteriormente as médias foram comparadas pelo teste de Tukey. As análises estatísticas foram realizadas com o auxílio do programa estatístico SAEG (EUCLYDES, 1983).

\section{RESULTADOS}

As respostas à aplicação de rizobactérias no substrato variaram de acordo com o clone de eucalipto e o isolado de rizobactéria testado. Em relação à biomassa radicular, apenas no clone 57 não foi observado incremento significativo nessa variável. Dentre os isolados de rizobactérias testados, o $\mathrm{S} 1$ foi o mais efetivo, independentemente do clone de eucalipto avaliado. Todavia, os ganhos variaram conforme o material genético, sendo em média iguais a 52,7; 52,1; e 69,0\% nos clones 129, 1274 e 7074, respectivamente. No clone 129, outros isolados promoveram incrementos significativos, como os isolados FL2 e MF2. Analogamente, obtiveram-se ganhos intermediários no clone 1274, quando as mudas foram produzidas em substrato tratado com os isolados de rizobactérias FL2, 3918 e MF2. Nos clones 1274 e 7074 , todos os isolados diferiram significativamente do tratamento-testemunha (Figura 1).

Em geral, observaram-se diferenças significativas na produção de miniestacas, mas não no índice de produtividade. Em relação à produção de miniestacas, no clone 57 não foram constatados incrementos significativos (Figura 2). Nos demais clones, o isolado $\mathrm{S} 1$ destacou-se entre os tratamentos com rizobactérias, com incrementos que variaram de 11,4 a 23,0\% nos clones 129 (Figura 3) e 1274 (Figura 4), respectivamente. No clone 7074 , o incremento médio foi de $15,4 \%$ (Figura 5).

\section{DISCUSSÃO}

Os resultados evidenciaram, dependendo do clone de eucalipto, o efeito de rizobactérias sobre o crescimento de mudas de eucalipto, expresso pela biomassa radicular e sobre a produção de miniestacas. Todavia, quando miniestacas coletadas de área de minijardim tratado com rizobactérias foram estaqueadas em substrato nãotratado, não foram observados incrementos significativos no índice de enraizamento, refletido no índice de produtividade. Tais observações permitem concluir que, aparentemente, esses isolados de rizobactérias dependem da sua presença na rizosfera para estimular o crescimento das plantas de eucalipto e que o seu efeito não é sistêmico.

Considerando os ganhos médios (16,6\% somente nos clones de resposta e $12,4 \%$ considerando todos os clones) em relação à produção de miniestacas, a tecnologia de utilização de rizobactérias para formação de minijardim clonal de eucalipto desponta como mais uma alternativa promissora. Aparentemente, o aumento na produtividade está relacionado à melhoria nas condições vegetativas das plantas-matrizes. Isso porque ficou evidenciado que plantas de eucalipto produzidas em substrato tratado com rizobactérias, especialmente com os isolados $\mathrm{S} 1$ e 3918, apresentaram maior desenvolvimento do sistema radicular e, portanto, maior suporte fisiológico para produção. 
A

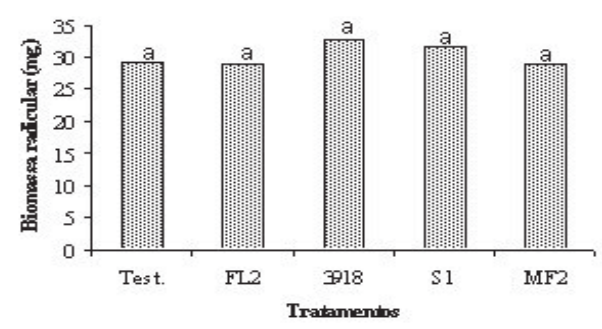

$\mathrm{C}$

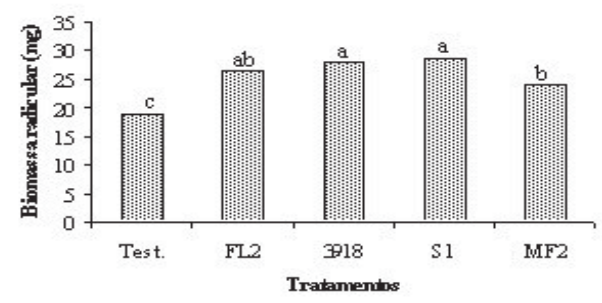

B

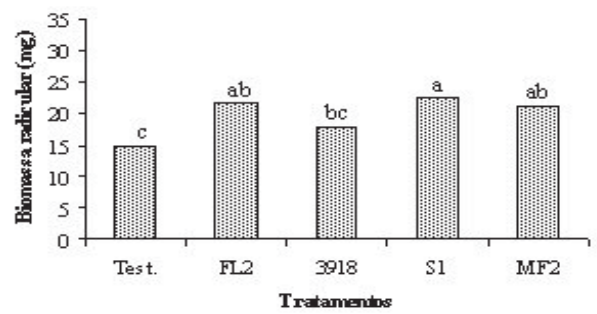

D

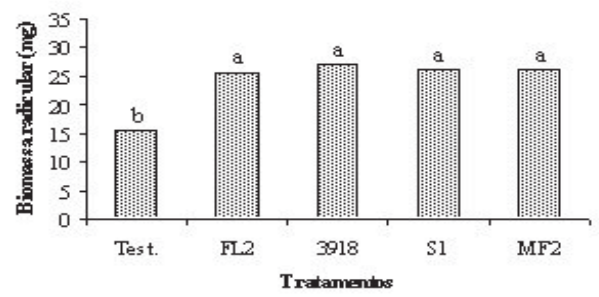

Figura 1 - Biomassa radicular seca por miniestaca enraizada dos clones 57 (A), 129 (B), 1274 (C) e 7074 (D) após o estaqueamento em substrato tratado com diferentes isolados de rizobactérias. Colunas sob a mesma letra não diferem estatisticamente entre si, pelo teste de Tukey $(\mathrm{P}<0,05)$. CV $(\%)=28,3,20,5,10,9$ e 11,3 , respectivamente.

Figure 1 - Dry root biomass per rooted mini-cutting of clones $57(A), 129(B), 1274(C)$ and $7074(D)$ in substrate treated with different rhizobacterium isolates. In the same column means followed by the same letter did not differ statistically by the Tukey's test $(p<0.05) . C V(\%)=28.3,20.5,10.9$ e 11.3, respectively.

A
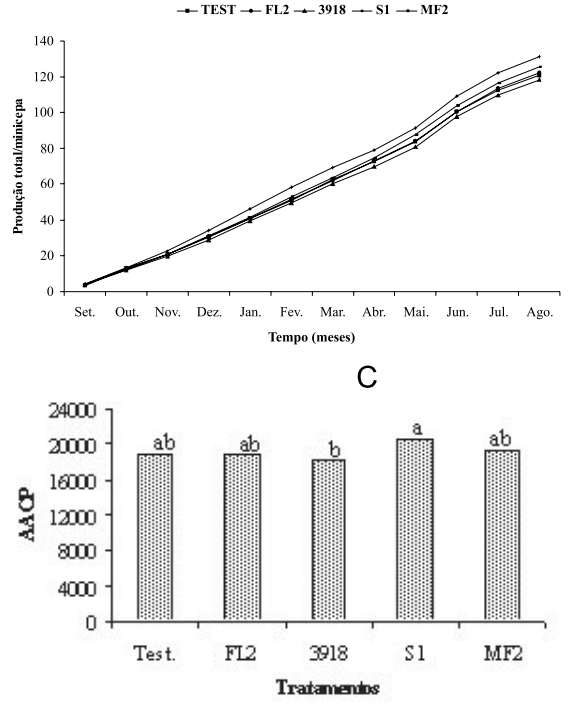

B

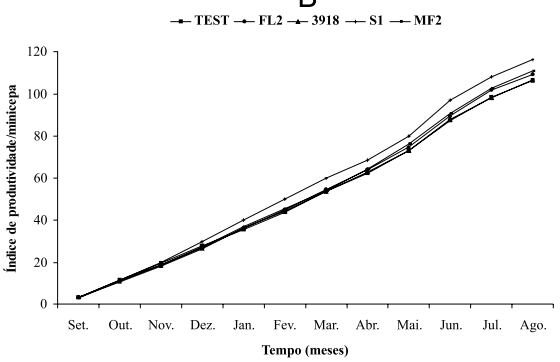

$\mathrm{D}$

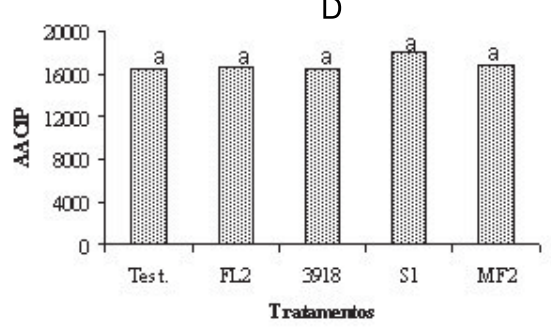

Figura 2 - Produção acumulada de brotos por minicepas (A), índice de produtividade por minicepa (B), área abaixo da curva de produção (C) e área abaixo da curva do índice de produtividade (D) do clone 57 . Colunas sob a mesma letra não diferem estatisticamente entre si, pelo teste de Tukey $(\mathrm{P}<0,05)$. CV $(\%)=5,3$ e 5,6, respectivamente.

Figure 2 - Accumulated production of shoots per mini-stump (A), productivity index per mini-stump (B), area under the production curve $(C)$ and area under the productivity index curve $(D)$ for clone 57 . In the same column means followed by the same letter did not differ statistically by the Tukey's test $(p<0.05) . C V(\%)=5.3$ e 5.6 respectively. 
A

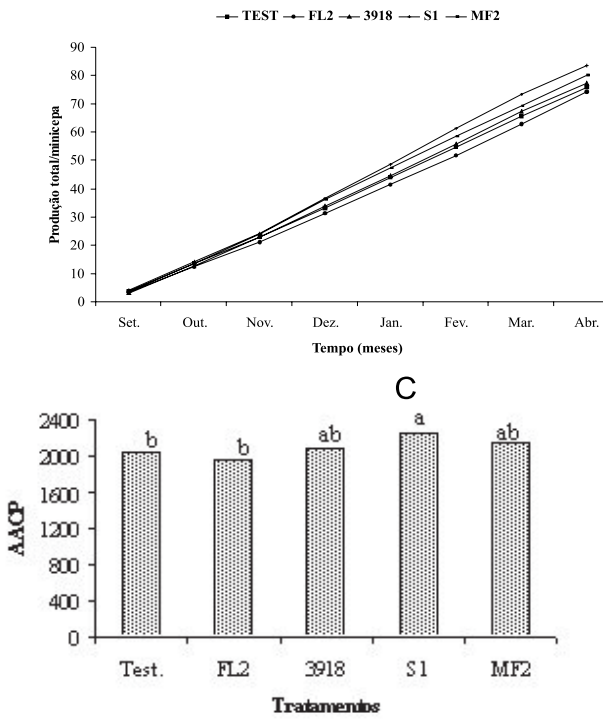

B

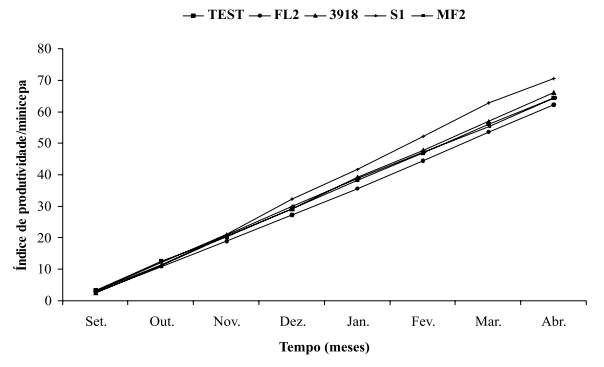

D

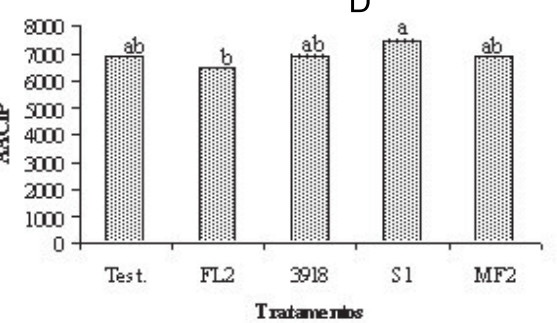

Figura 3 - Produção acumulada de brotos por minicepas (A), índice de produtividade por minicepa (B), área abaixo da curva de produção (C) e área abaixo da curva do índice de produtividade (D) do clone 129. Colunas sob a mesma letra não diferem estatisticamente entre si, pelo teste de Tukey $(\mathrm{P}<0,05) . \mathrm{CV}(\%)=5,5$ e 6,9, respectivamente.

Figure 3 - Accumulated production of shoots per mini-stump (A), productivity index per mini-stump (B), area under the production curve $(C)$ and area under the productivity index curve $(D)$ for clone 129 . In the same column means followed by the same letter did not differ statistically by the Tukey's test $(p<0.05)$. $C V(\%)=5.5$ e 6.9, respectively.

A

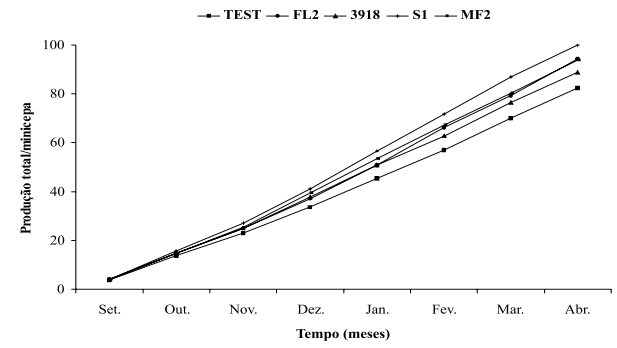

C

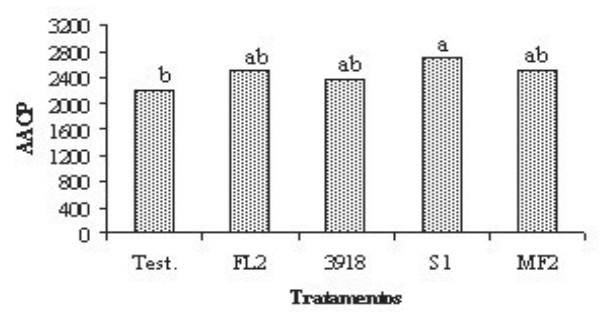

B

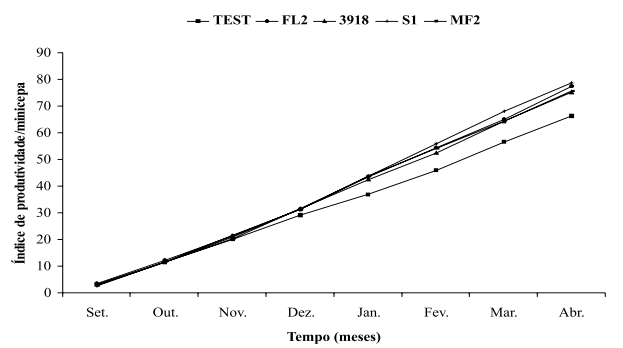

$\mathrm{D}$

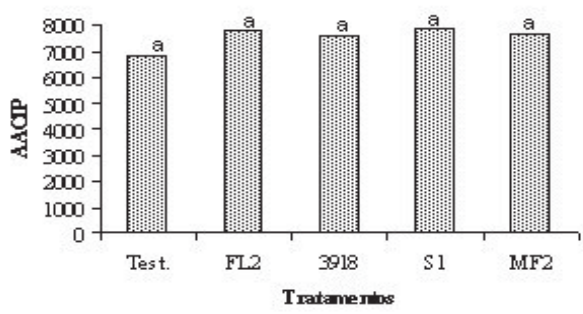

Figura 4 - Produção acumulada de brotos por minicepas (A), índice de produtividade por minicepa (B), área abaixo da curva de produção (C) e área abaixo da curva do índice de produtividade (D) do clone 1274. Colunas sob a mesma letra

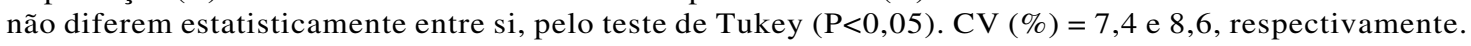

Figure 4-Accumulated production of shoots per mini-stump (A), productivity index per mini-stump (B), area under the production curve $(C)$ and area under the productivity index curve $(D)$ for clone 1274 . In the same column means followed by the same letter did not differ statistically by the Tukey's test $(p<0.05) . C V(\%)=7.4$ e 8.6 respectively.

R. Árvore, Viçosa-MG, v.29, n.6, p.843-851, 2005 
A

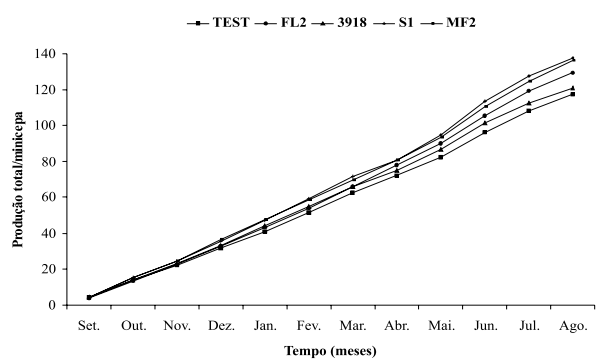

$\mathrm{C}$

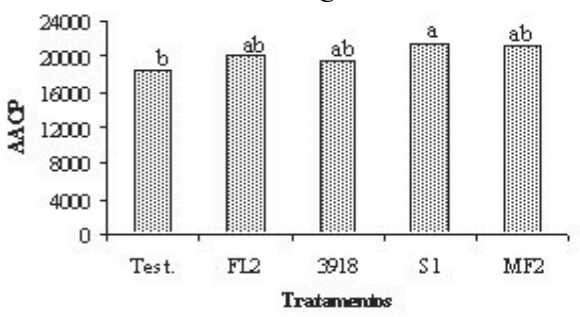

B

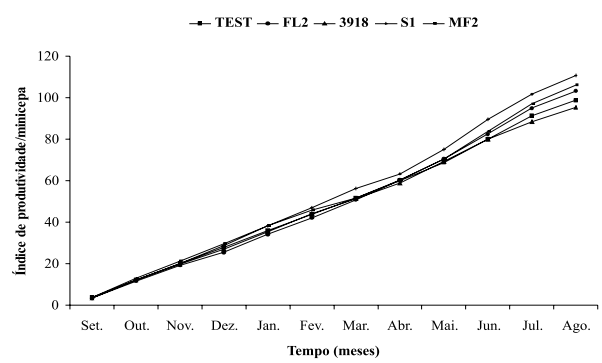

$\mathrm{D}$

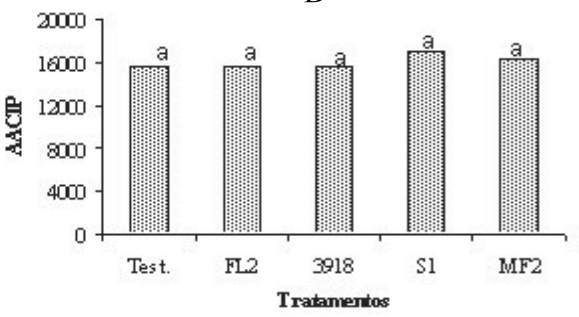

Figura 5 - Produção acumulada de brotos por minicepas (A), índice de produtividade por minicepa (B), área abaixo da curva de produção (C) e área abaixo da curva do índice de produtividade (D) do clone 7074. Colunas sob a mesma letra não diferem estatisticamente entre si, pelo teste de Tukey $(\mathrm{P}<0,05)$. CV $(\%)=6,8$ e 9,2, respectivamente.

Figure 5 - Accumulated production of shoots per mini-stump (A), productivity index per mini-stump (B), area under the production curve $(C)$ and area under the productivity index curve $(D)$ for clone 7074 . In the same column means followed by the same letter did not differ statistically by the Tukey's test $(p<0.05) . C V(\%)=6.8$ e 9.2 respectively.

Dentre os clones testados, apenas o 57 não respondeu significativamente ao tratamento com rizobactérias em relação à biomassa radicular, provavelmente em função da elevada capacidade produtiva desse clone ou da inexistência de um isolado específico de rizobactéria entre aqueles empregados neste estudo. Um trabalho conduzido com lentilha e ervilha evidenciou diferenças na habilidade de promoção de crescimento mediado por dois isolados de rizobactérias, o que foi atribuído, em parte, ao efeito do genótipo da planta (CHANWAY et al., 1989).

A interação entre isolados de rizobactérias e genótipos da planta de interesse é muito estudada (KLOEPPER, 1996) e aparentemente não existe consenso sobre o assunto. Isolados de Pseudomonas e Arthrobacter, sabidamente colonizadores do sistema radicular e estimuladores do crescimento de canola (Brassica campestris L. e B. napus L.), foram efetivos em incrementar a altura e biomassa de plantas de abetonegro (Picea mariana (Mill.) B.S.P.) e branco (Picea glauca (Moench) Voss) após a inoculação de raízes ou mudas (CHANWAY, 1997). Além disso, quando isolados selecionados por induzir resistência sistêmica na cultura do pepino e tomate foram empregados para inoculação de espécies de Pinus, observou-se efeito significativo na velocidade de germinação das sementes, na biomassa da parte aérea e no número de ramos por planta de Pinus taeda L. e no peso e altura da parte aérea de Pinus elliottii Engelm, a depender do isolado empregado (LIU et al., 1995; WEI et al., 1996). Em outros estudos, no entanto, parece haver especificidade de resposta para espécies arbóreas tratadas com rizobactérias promotoras do crescimento, que aparentemente depende das condições de ambiente e geográficas do local de estudo(O’NEILLet al., 1992; CHANWAY e HOLL, 1993). Assim, isolados promotores de crescimento em uma espécie de planta podem não ser efetivos em outras (SCHROTH e HANCOCK, 1982). Diferenças na quantidade e qualidade de exsudatos radiculares de diferentes espécies de plantas, bem como de cultivares e genótipos de uma mesma espécie, têm sido relatadas como a causa dessas variações (BALDANI e DOBEREINER, 1980; SHISHIDO e CHANWAY, 1999). 


\section{CONCLUSÕES}

A produção de mudas de eucalipto em substrato tratado com rizobactérias pré-selecionadas, para posterior formação de minicepas, poderá aumentar a produção de brotos, dependendo do isolado de rizobactéria e clone de eucalipto.

O efeito promotor de crescimento não foi sistêmico, havendo a necessidade de aplicação dos isolados em substrato de enraizamento.

A utilização de rizobactérias benéficas poderá ser empregada com o intuito de maximizar a propagação do eucalipto, por meio da otimização das condições de crescimento das plantas-matriz em minijardim clonal.

\section{AGRADECIMENTOS}

Às empresas florestais Aracruz Celulose S.A., CAF Santa Bárbara Ltda., Cenibra S.A., International Paper do Brasil, Jari Celulose S.A., Lwarcel Celulose e Papel Ltda., Plantar S.A., Cia. Suzano Bahia Sul Celulose S.A. e Veracel Celulose S.A., pelo apoio logístico e pelo financiamento da pesquisa que deu origem a este trabalho.

\section{REFERÊNCIAS BIBLIOGRÁFICAS}

ALFENAS, A.C. et al. Clonagem e doenças do eucalipto. Viçosa, MG: UFV, 2004. 442p.

ASSIS, T.F. Evolution of technology for cloning Eucalyptus in large scale. In: IUFRO INTERNATIONAL SYMPOSIUM, 2001, Valdivia. Proceedings... Chile: EMBRAPA/ CNPF, 2001. p.22.

BALDANI, V.L.D.; DOBEREINER, J. Host plant specificity in the infection of cereals with Azospirillum spp. Soil Biology and Biochemistry, v.12, p.433-439, 1980.

BROWN, M.E. Seed and root bacterization. Annual Review of Phytopathology, v. 12, p.181-197, 1974.

BUCHENAUER, H. Biological control of soilborne diseases by rhizobacteria. Journal of Plant Disease and Protection, v. 105, p.329-348, 1998.

CAMPBELL, C.L.; MADDEN, L.V. Introduction to plant disease epidemiology. New York: John Willey \& Sons, 1990. 532p.

R. Árvore, Viçosa-MG, v.29, n.6, p.843-851, 2005
CHANWAY, C.P.; HOLL, F.B. Ecotypic specificity of spruce emergence-stimulating Pseudomonas putida. Forest Science, v.39, p.520-527, 1993.

CHANWAY, C.P. Inoculation of tree roots with PGPR soil bacteria: an emerging technology for reforestation. Forest Science, v.43, p.99-112, 1997.

CHANWAY, C.P.; HYNES, R.K.; NELSON, L.M. Plant growth promoting rhizobacteria: effects on growth and nitrogen fixation of lentil (Lens esculenta Moench) and pea (Psium sativum L.). Soil Biology Biochemistry, v.21, p.511-517, 1989.

De LEIJ, F.A.A.M.; LYNCH, J.M. Functional diversity of the rhizosphere. In: INTERNATIONAL WORKSHOP ON PLANT GROWTH-PROMOTING RHIZOBACTERIA, 4., 1997, Sapporo.

Proceedings... Japan:OECD Joint Workshop, 1997. p.38-43.

De LEIJ, F.A.A.M. et al. Field release of a genetically modified Pseudomonas fluorescens on wheat: establishment, survival and dissemination. Bio/Technology, v.13, p.1488-1492, 1995.

ELLIS, J.G. et al. Agrobacterium: genetic studies on agromycin 84 production and the biological control of crown gall. Physiology Plant Pathology, v.15, p.311-319, 1979.

EUCLYDES, R.F. Manual de utilização do programa SAEG (Sistema para Análises Estatísticas e Genéticas). Viçosa, MG:UFV, 1983. 59p.

GLICK, B.R. The enhancement of plant growth by free-living bacteria. Canadian Journal of Microbiology, v.41, p.109-117, 1995.

GLICK, B.R. et al. 1-Aminocyclopropane-1carboxylic acid deaminase mutants of the plant growth promoting rhizobacterium Pseudomonas putida GR 12-2 do not stimulate canola root elongation. Canadian Journal of Microbiology, v.40, p.911-915, 1994.

GLICK, B.R.; KARATUROVIC, D.M.; NEWELL, P.C. A novel procedure for rapid isolation of plant growth-promoting pseudomonads. Canadian Journal of Microbiology, v.41, p.533-536, 1995. 
HALL, J.A. et al. Root elongation in various agronomic crops by the plant growth promoting rhizobacterium Pseudomonas putida GR 12-2. Israel Journal Plant Science, v.44, p.37-42, 1996.

KADO, E.I.; HESKETT, M.G. Selective media for isolation of Agrobacterium, Corynebacterium, Erwinia, Pseudomonas and Xanthomonas.

Phytopathology, v.60, p.969-976, 1970.

KLOEPPER, J.W. Host specificity in microbe-microbe interactions. BioScience, v.46, p.406-409, 1996.

KLOEPPER, J.W.; LIFSHITZ, R.; ZABLOTOWICZ, R.M. Free-living bacteria inocula for enhancing crop productivity. Trends Biotechnology, v.7, p.39-43, 1989.

LEINHOS, V.; VACEK, O. Biosynthesis of auxins by phosphate-solubilizing rhizobacteria from wheat and rye. Microbiology Research, v.149, p.31-35, 1994.

LIU, L.; KLOEPPER, J.W.; TUZUN, S. Induction of systemic resistance in cucumber by plant growthpromoting rhizobacteria: duration of protection and effect of host resistance on protection and root colonization. Phytopathology, v.85, p.1064-1068, 1995.

LOPER, J.E.; SCHROTH, M.N. Influence of bacterial sources of indole-3-acetic acid on root elongation of sugar beet. Phytopathology, v.76, p.386-389, 1986.

O'NEILL, G.A. et al. An assessment of spruce growth response specificity after inoculation with coexistent rhizosphere bacteria. Canadian

Journal of Botany, v.70, p.2347-2353, 1992.

PAN, B. et al. Plant-growth-promoting rhizobacteria and kinetin as ways to promote corn growth and yield in a short-growing-season area. European Journal of Agronomy, v.11, p.179-186, 1999.

PATTEN, C.L.; GLICK, B.R. Bacterial biosynthesis of indole-3-acetic acid. Canadian Journal of Microbiology, v.42, p.207-220, 1996.
PIAO, C.G.; TANG, W.H.; CHEN, Y.S. Study on the biological activity of yield-increasing bacteria. China Journal of Microbiology, v.4, p.55-62, 1992.

PRIKRYL, Z.; VANCURA, V.; WURST, M. Auxin formation by rhizosphere bacteria as a factor of root growth. Biologia Plantarum, v.27, p.159-163, 1985.

SALAMONE, I.E.G.; NELSON, L.; BROWN, G. Plant growth promotion by Pseudomonas PGPR cytokinin producers. In: INTERNATIONAL WORKSHOP ON PLANT GROWTH-PROMOTING RHIZOBACTERIA, 4., 1997, Sapporo. Proceedings... Sapporo: OECD Joint Workshop, 1997. p.316-319.

SCHROTH, M.N.; HANCOCK, J. Disease suppressive soil and root colonizing bacteria. Science, v.216, p.1376, 1982.

SHISHIDO, M.; CHANWAY, C.P. Spruce growth response specificity after treatment with plant growth promoting Pseudomonas. Canadian Journal of Botany, v.77, p.22-31, 1999.

TEIXEIRA, D.A. Promoção de enraizamento e indução de resistência sistêmica à ferrugem e à mancha-deCylindrocladium, mediadas por rizobactérias em clones de Eucalyptus spp. 2001. 67f. Tese (Doutorado em Fitopatologia), Universidade Federal de Viçosa, Viçosa, 2001.

VOISARD, C. et al. Cyanide production by Pseudomonas fluorescens helps suppress root rot of tobacco under gnotobiotic conditions. EMBO Journal, v.8, p.351-358, 1989.

WEI, G.; KLOEPPER, J.W.; TUZUN, S. Induced systemic resistance to cucumber diseases and increased plant growth by plant growth-promoting rhizobacteria under field conditions.

Phytopathology, v.86, p.221-224, 1996. 